\title{
The Influence of Foreign Direct Investment and Economic Development on Environmental Pollution
}

\author{
Yunxiu Qiu ${ }^{1, *}$, Jianjun $\mathrm{Niu}^{2}$, Like Zhang ${ }^{3}$ \\ ${ }^{I}$ School of Economics and Management, Shandong Youth University of Political Science \\ ${ }^{2}$ School of Economics and Management, Shandong Youth University of Political Science \\ ${ }^{3}$ School of Economics and Management, Shandong Youth University of Political Science \\ ${ }^{*}$ Corresponding author. Email: 6548738@qq.com
}

\begin{abstract}
Foreign direct investment has driven the growth of China's economy, but also caused many environmental problems, threatening the health of residents, restricting the further economic development. Striking a balance between the economy, FDI and the environment to achieve sustainable growth is an urgent task. To study whether FDI and economic growth cause pollution to the environment; the data of Chinese autonomous regions from 2010 to 2019 were selected as the research sample, with sulfur dioxide as the pollutant index, per capita GDP as the economic level index, and the actual amount of foreign capital used as the FDI index. The relationship between FDI, economic growth and environmental pollution in China is empirically analyzed, and the relationship between them and environmental quality is further determined by comprehensively considering industrial structure, capital-labor ratio, environmental management level and other indicators. It concludes that FDI correlates with environmental pollution. There is a positive correlation between economic growth and environmental pollution. The industrial structure, capital labor rate and environmental pollution positively correlate, while the pollution control level and environmental pollution negatively correlate.
\end{abstract}

Keywords: Foreign direct investment, Economic growth, Environmental pollution

\section{INTRODUCTION}

Under the background of economic globalization, foreign direct investment plays an important role in China's economic development. However, China has a large population and insufficient resources, some areas still have serious environmental pollution in the process of development. Therefore, it is of great practical significance to promote China's stable, healthy and sustainable economic development, while understanding the relationship between foreign direct investment and China's environment. Since the reform and opening up, China has made great achievements in attracting foreign investment. Do foreign direct investment and economic growth pollute the environment? Scholars have conducted various studies, but they have not reached a unified conclusion. From the literature, most studies had concluded that foreign direct investment had a negative impact on the environment when they took water pollution as a measure of environmental pollution. Taking $\mathrm{SO} 2$ as a measure of environmental pollution, most studies concluded that foreign direct investment had a positive impact on China's environment.

\section{LITERATURE REVIEW}

\subsection{Review of Foreign Research}

Foreign Studies on the relationship between environment, economic growth and foreign direct investment mostly focus on developing countries.

Anis Omri, Duc Khuong Nguyen, Christophe Rault(2014) ${ }^{[1]}$ selected the data of 54 countries from 1990 to 2011 to test the causal relationship between carbon dioxide emissions, FDI and economic growth. The conclusion showed that FDI and $\mathrm{CO} 2$ were twoway causality in most regions. Except the Middle East, North Africa and black Africa, $\mathrm{CO}_{2}$ and economic growth were two-way causality.

Chor Foon Tang, Bee Wah Tan(2015) ${ }^{[2]}$ used Vietnam's data from 1976 to 2009 and studied the relationship between FDI, energy consumption, 
economic growth and $\mathrm{CO}_{2}$ emissions. The results showed that the impact of energy consumption on $\mathrm{CO}_{2}$ was positive, while the square of the two variables had a negative impact on $\mathrm{CO}_{2}$, which proved the hypothesis that the EKC curve inverted U-shaped. There was a causal relationship between carbon dioxide emissions, income and FDI. Both in the short and long term, it showed that energy consumption was the cause of carbon dioxide emission. Therefore, it was important to accept some foreign investment in clean energy for carbon dioxide emission and maintaining sustained and stable economic growth.

FahriSeker, Hasan Murat Ertugral, Murat Cetin $(2015)^{[3]}$ researched the impact of FDI, regional GDP and energy consumption on $\mathrm{CO}_{2}$ emissions in Turkey. In the long term, there was a significant correlation between FDI and carbon dioxide emissions, but the correlation was small. However, GDP and energy consumption had a great impact on carbon dioxide emissions. The results showed that it was necessary for Turkey to improve its energy sustainable development policy and encourage the introduction of more FDI, especially when environment-friendly and technology intensive FDI could improve environmental quality.

Hui ming Zhu, Lijun Duan, Yawei Guo, Keming Yu (2016) ${ }^{[4]}$ researched the impact of FDI, energy consumption and economic growth on carbon dioxide emissions of Indonesia and other five countries. FDI reduced carbon dioxide emissions. In high emission countries, better economy growled and more people could reduce emissions. This result confirmed that the pollution halo hypothesis was correct in some countries with high emissions.

\subsection{Review of Domestic Research}

Wang Baijie and Zhou Bin (2018) ${ }^{[5]}$ analyzed the production and pollution model of Copeland and Taylor [6], and built a model to verify its comprehensive effect and threshold effect. The research showed that the impact of FDI and trade on the environment was different. The impact of trade on the environment was positive, and there was a positive correlation between FDI and environmental pollution. The combined effect of trade and FDI showed that export trade reduces environmental pollution, while FDI increased pollution emissions. It could reduce the negative impact on the environment by expanding FDI.

Liu Yilin (2019) ${ }^{[7]}$ analyzed the data of FDI and water pollution. The conclusion showed that FDI inflow positively correlated with water pollution, and the increase of FDI would aggravate the pollution of water environment.

Wu You (2019) ${ }^{[8]}$ established an empirical model, carried out baseline regression at the national and regional levels, and used the variable substitution method to replace the main explanatory variables and explained variables for robustness test. It concluded that FDI was not the direct cause of China's environmental pollution, and FDI had improved China's environmental pollution during the study period. There was a significant and complex interaction between FDI and environmental regulation, which havd a significant impact on pollutant emission.

Han Xiaohan (2020) ${ }^{[9]}$ studied the impact of FDI and environmental regulation and made a comparative analysis on the regional differences between eastern and central urban agglomerations. FDI had an obvious negative correlation with ecological efficiency, and proved the existence of pollution shelters. There was a significant correlation between environmental regulation and ecological efficiency. This showed that environmental regulation had innovative incentives and benefits in ecological efficiency. The interaction between FDI and environmental regulation had a significant positive correlation in ecological efficiency.

Zhou Jieqi, Zhang Ying (2021) ${ }^{[10]}$ studied the mechanism of FDI on the efficiency of green economy. FDI had dual benefits in green economic efficiency. Through the industrial structure, it had a negative effect, and showed a positive effect through economic agglomeration and energy-saving and emission reduction technologies. As a whole, FDI was conducive to the improvement of green economic efficiency. This was because economic concentration would weaken the benefits of FDI industrial structure and strengthen the technical benefits of energy conservation and emission reduction. If the degree of economic agglomeration was appropriate, FDI and economic agglomeration formed a synergistic effect, improved the efficiency of green economy. There were obvious regional differences in the impact of FDI on the efficiency of green economy.

\section{MECHANISM}

There are two main ways for FDI to affect environmental pollution theoretically. First, the production pollution of foreign-funded enterprises directly affects the local environment. Second, FDI affects other factors on the environment through the transmission mechanism. Based on Grossman and Krueger (1991) [11], this paper analyzed the environmental effects of FDI in China's decentralization system from the perspectives of scale, structure and technology.

\subsection{Economic scale effect}

On the one hand, local governments participate in FDI competition at the cost of environment in order to pursue economic growth and surface performance. On the other hand, economic scale growth is the carrier of FDI introduction, which reduces unit energy 
consumption through the effect of increasing output scale. Similarly, M \& A or enterprise reorganization can improve pollution control efficiency to improve regional environmental quality.

\subsection{Industrial structure effect}

On the one hand, the investment importing countries need to raise environmental standards, attract foreign capital to industries with low pollution and promote the development of these industries. On the other hand, investment-importing countries reduce environmental standards in order to attract FDI, which will inevitably bring new burden to the local ecological environment. In addition, environmental regulators (local governments) also have a policy burden. Therefore, regulated companies (foreign companies) may improperly capture environmental regulators and make them relax environmental regulation.

\subsection{Technology spillover effect}

Strict local environmental regulations require FDI to reduce its own pollutant emissions by taking advantage of its advanced environmental protection technology. In addition, the environmental protection technology brought by FDI inflow can promote the cleaner production of local companies and improve the pollution control technology of the industry through competition, demonstration and learning effects, bringing positive technology spillover effects to the local environment. Local governments prefer to use low-cost land and large-scale infrastructure to participate in the competition for investment. This competitive model costs a lot of money and some irrecoverable costs. In order to fill the financial vacancy, it will occupy local economic resources through tax financial power, and occupy the corresponding investment in environmental protection, which is not conducive to the innovation of environmental governance technology. In order to achieve short-term tax benefits, some local governments reduce the cost of introducing foreign capital, cannot resist the temptation of transferring low-cost technologies, and introduce a large number of outdated and harmful technologies, which will weaken the technology spillover effect of FDI.

\section{DATA AND MODEL}

\subsection{Variable Selection}

Environmental pollution index $(\mathrm{P})$ : there is no unified standard in the academic field for the indicators used to study environmental problems. The pollution of exhaust gas is the most serious in China's environmental pollution, so the harm of air pollution is the greatest. By consulting the research literature on air pollution at home and abroad, this paper extracts the emission of representative exhaust gas index $\mathrm{SO}_{2}$. The stability of emissions and the specificity of representative models will enhance.

FDI (X): according to the research of scholars, it finds that the impact of foreign investment on China's environment, but the relevant research has not reached a unified conclusion. For domestic research on FDI, the selected indicators divide into FDI flow and FDI stock. Considering that FDI stock can more accurately reflect the impact of FDI on environmental pollution, this paper will choose FDI stock (US \$100 million) to study.

Economic development level (Y): in the research on EKC hypothesis, per capita income is a representative indicator of economic growth. In the traditional empirical analysis of EKC hypothesis, per capita GDP is the explanatory variable, referring to the empirical research made by Akbostanci ${ }^{[12]}$.

Industrial structure $(\mathrm{T})$ : China's industrial construction is in a period of deep development, which is a strong driving force for economic growth. At the same time, industry is also the main source of pollution.

Capital / labor force (KL): the use of factor products with increasing proportion is higher than that of factor products with constant proportion. Therefore, the increase of per capita capital stock will lead to the increase of pollutant emission, which will lead to the increase of $\mathrm{SO} 2$ emission.

Environmental governance level (I): the global attention to environmental issues has gradually increased, countries and regions have increased their investment in environmental management, and the management results are obvious. The level of environmental management is also an important factor affecting the environment.

\subsection{Data}

China Statistical Yearbook compiles the data from 2010 to 2019. The data selected in this paper are from the database of the National Bureau of statistics and China Environmental Statistical Yearbook.

\subsection{Model}

According to the empirical analysis of EKC curve in the past and based on the available research literature, $\mathrm{SO} 2$ is the explanatory variable. Based on the empirical model of Akbostanci ${ }^{[14]}$, the explanatory variable economic growth selects per capita GDP and its square. In addition, other factors affecting pollution should be considered. Establish the following model:

$\operatorname{lnp}_{\mathrm{t}}=\beta_{0}+\beta_{1} \ln \mathrm{x}_{\mathrm{t}}+\beta_{2} \operatorname{lny}^{2}+\beta_{3} \ln y_{\mathrm{t}}+\beta_{4} \mathrm{t}_{\mathrm{t}}+\beta_{5} \operatorname{lnk}_{\mathrm{t}}+\beta_{6} \mathrm{i}_{\mathrm{t}}+\mu_{\mathrm{t}}$ 
Note: $t$ represents the year; $\beta_{0}, \beta_{1}, \beta_{2}, \beta_{3}, \beta_{4}, \beta_{5}, \beta_{6}$ are the parameter to be estimated; $\mathrm{x}$ is FDI; $\mathrm{y}$ is economic growth; $\mathrm{t}$ is the industrial structure; $\mathrm{kl}$ is the capital labor ratio; i is pollution control level.

\section{THE EMPIRICAL ANALYSIS}

\subsection{Model Testing}

\subsubsection{Stationary test}

The data processing of this part mainly uses Eviews 8.0 software to test the stationarity of the above variables. Firstly, the logarithm of $\mathrm{x}, \mathrm{p}, \mathrm{y}$ and $\mathrm{kl}$ are taken, and the variables lnx, lnp, t, lny, lnkl, i and (lny) after taking the logarithm are included in the model. The unit root test (ADF) is selected to test the stability of the sequence, so as to avoid the pseudo regression phenomenon of the sequence. The results are shown in the table below. The results show that the logarithms of the seven variables are stable under the horizontal order. Therefore, the next cointegration test is carried out.

Table1. Stationarity test results

\begin{tabular}{|c|c|c|c|}
\hline Variable & ADF Test Value & $\mathrm{p} \mathrm{Value}^{\star}$ & Conclusion \\
\hline $\ln \mathrm{x}$ & -6.48462 & 0.004 & Smooth \\
\hline $\ln p$ & -3.21696 & 0.0574 & Smooth \\
\hline $\mathrm{t}$ & -3.85918 & 0.0016 & Smooth \\
\hline $\ln \mathrm{y}$ & -5.35667 & 0.012 & Smooth \\
\hline$(\operatorname{lny})^{2}$ & -4.3476 & 0.0134 & Smooth \\
\hline $\operatorname{lnkl}$ & -3.69755 & 0.0025 & Smooth \\
\hline $\mathrm{i}$ & -4.96902 & 0.0064 & Smooth \\
\hline
\end{tabular}

\subsubsection{Cointegration Test}

Before establishing the model, it is necessary to judge whether the variable relationship is stable through cointegration test, and determine whether there is cointegration relationship between the variables of time series data through $\mathrm{t}$ test and $\mathrm{Z}$ test, so that the model can reflect most of the interaction between variables. The E-G cointegration test in the selected cointegration test obtain from this result. From the E-G cointegration test results in the table below, the original hypothesis is rejecting at the confidence level of $10 \%$, that is, the six variables have cointegration relationship at the horizontal order. The specific results are showing in the table below.

Table 2. Co-integration Test Results

\begin{tabular}{|c|c|c|c|c|}
\hline DePendent & tau-statistic & Prob. $^{*}$ & z-statistic & Prob. $^{*}$ \\
\hline $\operatorname{Inp}$ & -2.590008 & 0.8860 & -8.080745 & 0.0368 \\
\hline Iny & -3.226071 & 0.7012 & -9.499542 & 0.0933 \\
\hline$(\text { Iny })^{2}$ & -2.375822 & 0.3984 & -14.95592 & 0.0009 \\
\hline
\end{tabular}

\begin{tabular}{|c|c|c|c|c|}
\hline $\ln x$ & -5.237600 & 0.1787 & -13.96886 & 0.0009 \\
\hline $\mathrm{t}$ & -3.304455 & 0.6746 & -9.832355 & 0.0793 \\
\hline $\operatorname{lnk} \mid$ & -3.796356 & 0.5251 & -142.8589 & 0.0072 \\
\hline $\mathrm{i}$ & -3.986839 & 0.4684 & -30.16481 & 0.0989 \\
\hline
\end{tabular}

\subsection{The Model Results}

In order to demonstrate in detail the influence of lny, its square term and $\operatorname{lnx}$ on the relevant variables of empirical research on lnp, this paper constructs a multiple regression model with $\operatorname{lnp}$ index as the explained variable and lnx, lny, (lny) 2 index as the main explanatory variable. The regression model mainly investigates the specific impact of each variable on lnp when other variables remain unchanged. In addition, in order to avoid t-test failure caused by heteroscedasticity error, this paper adopts the standard error method of robust clustering in time series data. The specific regression results are showing in the table below, involving the regression results of the impact on lnp. The implementation model is the specific impact of $\operatorname{lnx}$, lny and (lny) 2 on lnp.

The following table shows the specific regression results of each variable on lnp. From the following table, we can see that the adjusted R2 in the regression results of the model is 0.98 , indicating that the goodness of fit is better, and the explanatory power of the explanatory variables is statistically significant for the explanatory variables.

Table3. Regression results

\begin{tabular}{|c|c|c|c|c|}
\hline Variable & Coefficient & Std. Error & t-Statistic & Prob. \\
\hline $\ln x$ & 0.3932 & 0.0863 & 4.5574 & 0.0069 \\
\hline Iny & 0.1751 & 0.0465 & 3.7625 & 0.0328 \\
\hline$(\operatorname{lny})^{2}$ & -0.4401 & 0.1174 & -3.7498 & 0.0331 \\
\hline$T$ & 0.1411 & 0.0456 & 3.0949 & 0.0289 \\
\hline Inkl & 2.1492 & 0.7766 & 2.7676 & 0.0697 \\
\hline I & -0.3428 & 0.1499 & -2.2861 & 0.0842 \\
\hline C & 90.0619 & 25.9370 & 0.4723 & 0.0403 \\
\hline
\end{tabular}

The coefficient of lny is 0.1751 , and the original hypothesis is rejected at the $10 \%$ confidence level, indicating that there is a significant positive correlation between lny and lnp. This shows that economic growth is directly related to environmental pollution, and development will increase environmental pollution emissions. It can be seen from the model results that the coefficient of $\operatorname{lnx}$ is 0.774451 , and the original hypothesis is accepted at the confidence level of $1 \%$, indicating that there is a significant positive correlation between $\operatorname{lnx}$ and lnp. In reality, the mode of FDI is relatively open, the pollution emission standard is relatively low, and the foreign investment environment is relatively loose. With the increasing opening of trade, enterprises continue to expand production scale in order 
to improve international market share and economic benefits, which destroys the environment.

The coefficient of $\mathrm{T}$ is 0.1411 , and the original hypothesis is rejected at the $10 \%$ confidence level, indicating that there is a significant positive correlation between T and LNP. The coefficient of lnkl is 2.1492 . The original hypothesis is rejected at the $10 \%$ confidence level, which shows that there is a positive correlation between lnkl and LNP, and the impact of labor capital ratio and industrial structure on environmental pollution is positive. The coefficient of I is -0.3428 , and the original hypothesis is rejected at the $10 \%$ confidence level, indicating that there is a significant negative correlation between $i$ and lnp.

From the regression coefficient, the estimated coefficients of labor capital rate and industrial structure are positive. This shows that the improvement of labor capital ratio and industrial structure will lead to more serious environmental pollution. The above analysis results show that China needs to alleviate environmental pollution through economic structure adjustment, industrial structure optimization and per capita capital control. From the perspective of various coefficients, China also needs to adjust the common progress between economic growth, FDI and the environment through technological progress.

\section{CONCLUSION}

First, there is a positive correlation between FDI and environmental pollution, and FDI will aggravate environmental pollution.

Second, the relationship between economic growth and environmental pollution conforms to the inverse $\mathrm{U}$ curve of EKC curve.

Third, there is a positive correlation between industrial structure, capital labor rate and environmental pollution, and a negative correlation between pollution control level and environmental pollution.

\section{REFERENCES}

[1]Anis Omri, Duc Khuong Nguyen,Christophe Rault. Causal interactions between $\mathrm{CO} 2$ emissions, FDI, a nd economic growth: Evidence fro$\mathrm{m}$ dynamic simultaneous-equation models[J]. Economic Modelling 42(2014)382-389.

[2]Chor Foon Tang, Bee Wah Tan. The impact of energy consumption, income and for eign direct investment on carbon dioxide emissions in Vietnam[J]. Energy, 79(2015)447-454.

[3]Fahri Seker, Hasan Murat Ertugrul, Murat Cetin. The impact of foreign direct investment on environ mental quality: A bounds testing a- nd causality analysis for Turkey[J].

Renewable and Sustainable Energy Reviews 52(2015)347-356.

[4]Huiming Zhu,Lijun Duan, Yawei Guo,Keming Yu.Th e effects of FDI, economic growth and energy cons umption on carbon emissions in ASEAN-

5: Evidence from panel quantile regression[J].Econ omic Modelling 58(2018)237-248.

[5]Wang Baijie, Zhou Bin. Has the export of goods and foreign direct investment exacerbated the environmental pollution of the home country--Reverse investigation based on "pollution paradise hypothesis" [J]. Research on industrial economy, 2018 (03): 77-89

[6]Copeland B R. Taylor M S.(1994) Northsouth trade and the environment $[\mathrm{J}]$.

Quarterly journal of economics, $109,755-787$.

[7]Liu Yilin. Study on the impact of FDI on China's water environment pollution [D]. Shandong Normal University, 2019

[8]Wu you. Analysis of the impact of FDI and environmental regulation on China's environmental pollution [D]. Southwest University of Finance and economics, 2019

[9]Han Xiaohan. Study on the impact of FDI and environmental regulation on ecological efficiency [D]. Guilin University of technology, 2020

[10]Zhou Jieqi, Zhang Ying. FDI, economic agglomeration and green economic efficiency -theoretical analysis and China's experience [J]. Exploration of international economy and trade, 2021,37 (01): 66-82.

[11]Grossman, $\quad$ G. and Krueger, $\quad$ A. Environment impacts of a North American Free Tr ade Agreement. N BER.Working Paper No.3914.1991.

[12]Akbostanci E, TURUT-ASIK S, TUNC Gl. The relationship between income and environment in turkey: is there an environmental kuznets curve[J]. Energy policy, 2009(03):37. 